Ciencia y Educación, Vol. 4, No. 3, septiembre-diciembre, 2020

ISSN (impreso): 2613-8794•ISSN (en línea): 2613-8808

DOI: https://doi.org/10.22206/cyed.2020.v4i3.pp115-130

\title{
Representaciones sociales sobre interculturalidad en académicos universitarios: el caso de la Universidad Veracruzana
}

\author{
Social representations about interculturality in university \\ academics: the case of the Universidad Veracruzana \\ Miguel Angel Casillas Alvarado ${ }^{a}$ ORCID: 0000-0001-8194-7666 \\ Julio César López Jiménez ${ }^{b}$ ORCID: 0000-0003-2077-4276
}

Recibido: 19/02/2020 • Aprobado: 24/03/2020

Cómo citar: Casillas Alvarado, M. A., \& López Jiménez, J. C. (2020). Representaciones sociales sobre interculturalidad en académicos universitarios: el caso de la Universidad Veracruzana. Ciencia y Educación, 4(3), 115-130. Doi: https://doi.org/10.22206/ cyed.2020.v4i3.pp115-130

Resumen

Se exponen resultados de un estudio realizado con académicos de la Universidad Veracruzana (UV) y documentos oficiales de la misma, con el fin de conocer las representaciones sociales que se tienen sobre interculturalidad y si estas convergen en una visión en conjunto. Se trabajó con un enfoque mixto, se aplicó una encuesta conformada por tres preguntas; dos de ellas con respuestas de opción múltiple y una abierta. Para obtener el discurso institucional se utilizó la técnica de análisis de discurso a los documentos oficiales. La encuesta fue aplicada a 121 académicos de seis Áreas Ácadémicas de la UV, finalmente la información fue almacenada en Excel y analizada por el software IraMuTeQ. Al comparar las representaciones sobre interculturalidad de la institución y de sus académicos, encontramos una baja convergencia, que refleja un escaso grado de adhesión al discurso institucional, aunque los profesores sostengan prácticas interculturales.

Palabras clave: socialización; interacción cultural; academia, análisis del discurso.

\begin{abstract}
Results of a study carried out with academics from the Universidad Veracruzana (UV) and with their official documents are presented in order to know the social representations that exist about interculturality and if they converge in a joint vision. We worked with a mixed approach, a survey consisting of three questions was applied; two of them with multiple choice answers and one open. To obtain the institutional discourse, the discourse analysis technique was applied to official documents. The survey was applied to 121 academics, from six Academic Areas of the UV, finally the information was stored in Excel and analyzed by the IraMuTeQ software. When comparing the representations on interculturality of the institution and its academics, we find a low convergence that reflects a low degree of adherence to the institutional discourse, although the professors maintain intercultural practices.
\end{abstract}

Keywords: socialization; cultural interaction; academia, discourse analysis.

\footnotetext{
a Universidad Veracruzana, México

Correo-e: mcasillas@uv.mx

b Universidad Veracruzana, México

Correo-e: zS15012696@estudiantes.uv.mx
} 


\section{Introducción}

El presente artículo es producto de un trabajo de investigación desarrollado en la Universidad Veracruzana (UV) con un grupo de académicos que laboran en las seis áreas de conocimiento: Biológica-Agropecuaria, Humanidades, Técnica, Ciencias de la Salud, Artes y Económico-Administrativa. La intención es conocer las representaciones sociales sobre interculturalidad que comparten los académicos de la Universidad. Para entender la interculturalidad nos apoyamos en las definiciones de la UNESCO (2017), Mato (2009), Malaga (2016), Aguado (2011) y Velasco y Jablonska (2010), como un proceso de interacción entre dos o más culturas, estas culturas pueden desarrollarse en distintos espacios tales como, el hogar, la oficina, la escuela o entre comunidades indígenas y citadinas. (Mato, 2009).

A lo largo del documento se ha seleccionado la Teoría de las Representaciones Sociales fundada por S. Moscovici (1979), para dar sustento a la investigación y con el objetivo de comprender qué piensan, qué actitudes tienen y cómo valoran la interculturalidad los profesores, a partir del análisis de las subjetividades de los académicos de la UV.

La Universidad Veracruzana es la única universidad pública en México que tiene una sección intercultural. Esta disposición inclusiva se registra en los documentos oficiales de la institución. Este artículo tiene como propósito hacer visibles las representaciones sobre interculturalidad que tiene la UV, al mismo tiempo queremos indagar las representaciones de sus profesores, y finalmente, a través de un ejercicio comparativo, observar qué tanto coinciden las representaciones institucionales y las de los profesores.

Para la construcción de la representación institucional se procedió al análisis de los principales documentos oficiales de la Universidad Veracruzana: la Ley Orgánica, El Estatuto General, la Ley de Autonomía y el Código de Ética.

Para entender la importancia de la interculturalidad en la educación mexicana, hay que recordar lo expresado por Sylvia Schmelkes (2013):
Por eso acudimos al concepto de interculturalidad. No se trata de un concepto descriptivo, sino de una aspiración. Se refiere a la relación entre las culturas y la califica. La interculturalidad supone que entre los grupos culturales distintos existen vínculos basados en el respeto y desde planos de igualdad. La interculturalidad no admite asimetrías, es decir, desigualdades entre culturas mediadas por el poder, que benefician a un grupo cultural por encima de otro u otros. Como aspiración, la interculturalidad es parte de un proyecto de nación (Schmelkes, 2013, p. 5).

Al ser una aspiración, la interculturalidad en México funciona como un referente para disminuir la discriminación y la reproducción de las desigualdades sociales, según la Encuesta Nacional sobre Discriminación (ENADIS, 2017), la experiencia de haber sido discriminado o menospreciado en el último año a causa de algún motivo o característica personal resulta significativa, "se indagó por 10 rasgos distintos: tono de piel, manera de hablar, peso o estatura, forma de vestir o arreglo personal, clase social, lugar donde vive, creencias religiosas, sexo, edad, y orientación sexual" (ENADIS, 2017, p. 7).

A nivel nacional "20.2\% declaró haber sido discriminado en el último año, siendo la forma de vestir o arreglo personal, el peso o estatura, la edad y las creencias religiosas, el principal factor" (ENADIS, 2017 , p. 8). En Veracruz, en promedio " $21.65 \%$ de la población encuestada respondió haber sido discriminada por algún motivo o condición personal" (ENADIS, 2017, p. 10).

Tomando en cuenta los datos anteriores, es de importancia recalcar cómo la interculturalidad no se reduce a un tema exclusivo de valores abstractos o de la educación en general, sino comprende un conjunto de normas que salvaguardan la integridad de las personas.

Afortunadamente, existen múltiples marcos jurídicos, entre los que destacan a nivel nacional la Constitución Política de los Estados Unidos Mexicanos, la Ley General de Educación, la Ley General de los Derechos Lingüísticos de los Pueblos Indígenas, la 
Ley Federal para Prevenir y Eliminar la Discriminación. A nivel internacional, son referentes obligados la Declaración Universal de los Derechos Humanos (DUDH), la Convención internacional sobre la eliminación de todas las formas de discriminación racial, la Declaración de principios de la cooperación cultural internacional, el Convenio 169 de la Organización Internacional del Trabajo sobre pueblos indígenas y tribales en países independientes, la Declaración universal de la Organización de las Naciones Unidas para la Educación, la Ciencia y la Cultura sobre la diversidad cultural y la Declaración de las Naciones Unidas sobre los derechos de los pueblos indígenas (Casillas y Villar, 2006, pp. 81-109).

Estas manifestaciones permean en todos los sectores y estratos sociales, y las Instituciones de Educación Superior (IES) en México no son la excepción, por ende, la intención es conocer qué representaciones existen en la Universidad Veracruzana y entre sus académicos.

\section{Fundamentos teóricos}

Las representaciones sociales son una teoría que tiene sus inicios con el análisis de las representaciones colectivas propuesto por Emile Durkheim (1895) a finales del siglo xIx. En 1961 Serge Moscovici recupera la noción y la convierte en representaciones sociales para su trabajo de tesis titulado Psicoanálisis su imagen y su público. Sobre la base de esta teoría central ha habido muchos desarrollos, destacan las aportaciones de Jodelet $(1986,2000,2008)$ y de Abric (1994, 2005, 2008).

Moscovici (1979) define las representaciones sociales como un "corpus organizado de conocimientos y una de las actividades psíquicas gracias a las cuales los hombres hacen inteligible la realidad física y social, se integran un grupo o en una relación cotidiana de intercambios, liberan los poderes de su imaginación" (p. 18). Esto es, las representaciones sociales son sobre algún objeto que es entendido y conocido por los sujetos. Entender las representaciones sociales implica estudiar las dimensiones que las componen, Moscovici propone tres: campo de representación, actitud e información.
El campo de representación Moscovici (1979), "remite a la idea de imagen, de modelo social, al contenido concreto y limitado de las proposiciones que se refieren a un aspecto preciso del objeto de la representación" (p. 46) es decir: es aquella parte propia del objeto a interpretar, es lo que es, fuera de la interpretación personal.

Para Moscovici (1979) la información es "la organización de los conocimientos que posee un grupo con respecto a un objeto social" (p. 45), todo aquello que se conoce de un tema en específico, en este caso: la interculturalidad.

Para finalizar, se encuentra la dimensión de actitud, está definida por Moscovici (1979) como "la orientación global en relación con el objeto de representación social” (p. 32), la conceptualización es corta pero el desarrollo no; es decir, se comprende como todo aquel constructo valorativo que se tiene hacia algo, específicamente en nuestro caso hacia la interculturalidad.

Las representaciones sociales cumplen cuatro funciones fundamentales según Abric (1994).

Funciones de saber: es decir, son las que por excelencia le permiten al hombre establecer sistemas de comunicación en donde se demuestra el interés de conocer y difundir la información entre los integrantes de la sociedad.

Funciones identitarias: tener conocimiento y actitud en el campo es de importancia para establecer grupos dentro de la sociedad, ya que dependiendo de la construcción que se tenga sobre algún tópico será el colectivo al que se adhieren los individuos.

Funciones de orientación: esta función permite establecer una postura frente a algo.

Funciones justificadoras: son aquellas que fortalecen la representación que se tiene sobre un tema; es decir, refuerzan la postura sobre algo entre grupos y que se definen después de conocer los resultados del estudio sobre representaciones. 
Antes de empezar a conceptualizar sobre lo que es la interculturalidad para este artículo, es necesario establecer las bases en cuanto a la pluriculturalidad, la multiculturalidad, y la diversidad cultural, pues cabe destacar que no son procesos lineales, sino que se relacionan entre sí, siendo la interculturalidad la utopía.

UNESCO (2017) define a la diversidad cultural como, "la existencia de una amplia variedad de culturas en el mundo de hoy" (p. 15). La pluriculturalidad es comprendida como el espacio en el que existen varias culturas, aunque esto no significa tener contacto. La multiculturalidad, por otro lado, es una medida que busca la inclusión de los grupos culturales en un mismo territorio, mientras que lo intercultural "describe lo que ocurre cuando los miembros de dos o más grupos culturales distintos (sea por tamaño o nivel) interactúan o influencian a otro de alguna manera, ya sea en persona o a través de distintas formas de mediación" (UNESCO, 2017, p. 16).

Para este artículo recuperamos la noción sobre interculturalidad que propone Daniel Mato (2009), ya que una de nuestras intenciones es intentar deconstruir la idea de relacionarla solo con los indígenas. El autor la visualiza en su forma más amplia, como las relaciones que se crean entre los grupos de cualquier índole y espacio. Abonando a la concepción de la interculturalidad, se establece la información de la organización internacional que más trabajo de investigación y difusión ha realizado sobre interculturalidad, es decir, la Organización de las Naciones Unidas para la Educación, la Ciencia y la Cultura (UNESCO, 2017). Entre otros elementos relacionados con interculturalidad se mencionan los aportes desde las políticas, la educación y la inclusión (Velasco y Jablonska, 2010).

Casillas y Villar (2006), publicaron el libro Universidad Intercultural, modelo educativo, en el que hacen un recorrido por las universidades interculturales en el país, mencionando sobre la Universidad Veracruzana Intercultural lo siguiente:

La Universidad Veracruzana Intercultural es un Programa de la Universidad Veracruzana que surge con el apoyo de la Coordinación General de Educación Intercultural y Bilingüe y tiene por objetivo ofrecer una opción de educación superior pertinente a las necesidades de los jóvenes que habitan distintas regiones del estado de Veracruz. La puesta en marcha de este proyecto se formalizó el 26 de noviembre de 2004 con la firma de un Convenio Interinstitucional entre el rector de esta universidad y la CGEIB. Inició actividades en agosto de 2005. Integra estudiantes de ocho pueblos y lenguas indígenas: totonaca, náhuatl, zapoteco, mixteco, otomí, tseltal, tsotsil y maya (p. 248).

Sergio Téllez, — principal promotor de la Universidad Veracruzana Intercultural- Juan Sandoval y Octaviano González, (2006), en su artículo Intercultural University of Veracruz: a holistic project promoting intercultural education, mencionan los lineamientos que siguieron para formalizar lo que hoy se conoce como la Universidad Veracruzana Intercultural y sobre cómo los esfuerzos realizados, en cuanto a establecer redes de colaboración, dieron como fruto engrandecer lo que una vez surgió como programa intercultural en la Universidad Veracruzana. Esto marca el inicio de un proceso histórico en cuanto a la incorporación de la interculturalidad en la Universidad, no obstante, habría que preguntarse qué tanto se ha transformado dicho discurso y en qué nivel ha permeado en la comunidad estudiantil y magisterial.

Casillas, Badillo y Ortiz (2012), en Elementos para pensar en los estudiantes indígenas de la Universidad Veracruzana y su diversidad (p. 93), exponen las diferentes miradas para observar la diversidad del estudiantado. Comienza la discusión hablando sobre la edad, y al respecto dice:

pero esto ya no es cierto; en realidad, las instituciones de educación superior convencionales e interculturales (todas en su conjunto) se están transformando en la composición de sus grupos de edad, cada vez reciben a estudiantes de edades mayores que son portadores de una visión distinta (Casillas et al., 2012, p. 94). 
Otro elemento que menciona es el de género, en el cual habla sobre la población de estudiantes en las universidades y cómo estas han ido promoviendo los procesos de emancipación del género femenino; al respecto sobre la UV menciona:

la Universidad Veracruzana en números redondos tiene $50 \%$ de hombres y $50 \%$ de mujeres, en tanto que en la Universidad Veracruzana Intercultural se transforma la proporción: dos terceras partes son mujeres y una tercera parte son hombres en la mayoría de nuestras regiones (Casillas et al., 2012, p. 95).

Sobre el contexto regional invita a pensar cómo la ubicación geográfica cultural influye en el tipo de prácticas de los estudiantes y termina mencionando lo siguiente:

Aunque el discurso apunta a pensar en la escuela como un espacio donde está presente la diversidad cultural, aún no ha sido posible que en la práctica de la educación se vea reflejada esta condición pues los programas, los planes y las políticas educativas se implementan sin considerar el perfil de una región para acercarlos a las comunidades (Casillas et al., 2012, p. 96).

A su vez, hablar del contexto obliga a mencionar el origen social de los estudiantes, pues determina el tipo de prácticas y su forma de ver al mundo; sobre la UV expone que:

mientras que el currículo, la imagen, la idea, los ritmos escolares y el diseño de la Institución pertenecen a una universidad pensada para la élite. Esta consideración tiene que hacernos pensar, entonces, en la intensa diversificación de los orígenes sociales de los estudiantes, lo cual nos obliga a transformar la universidad profundamente para aproximarla a sus estudiantes reales (Casillas et al., 2012, pp. 96-97).

Acerca de la condición familiar afirma que "cada vez tenemos más estudiantes que son padres de familia, cada vez más tenemos una proporción importante de madres solteras, de chicas que son jefas de su propia familia" (Casillas et al., 2012, p. 96) También aporta en cómo la visión institucional debe dejar de percibir a los jóvenes como sujetos que solo viven para la escuela:

la universidad sigue siendo implacable, seguimos pensando en exámenes estandarizados, establecemos niveles de corte que siguen concibiendo de manera homogénea a los estudiantes cuando sus trayectorias son diversas. Siguen considerando que se va de un área a la otra en función de lo que está planeado sin considerar cómo están construidas las universidades físicamente, cuáles son sus diseños arquitectónicos y pensadas para qué tipo de actividad estudiantil (Casillas et al., 2012, p. 99).

Conocer sobre las representaciones sociales sobre interculturalidad en la Universidad Veracruzana es un recurso para crear políticas educativas sobre inclusión, y elaborar programas para la formación docente. Estas medidas coadyuvan a desarrollar los objetivos de desarrollo sostenible, destacando el cuarto que trata sobre la calidad en la educación, el quinto sobre la igualdad de género y el décimo sobre la reducción de las desigualdades (UNESCO, 2015).

Finalmente, se presenta un breve estado de la cuestión en el que se exponen investigaciones con contenido similar al aquí expuesto, por ejemplo, la tesis de maestría de Ilse Hernández (2017) en el CIESAS, o tal como lo hace Tipa (2017), en el texto “¿La interculturalidad es más que una palabra? La interculturalidad según estudiantes de la Universidad Intercultural de Chiapas" donde realizó un estudio en el que identificó las concepciones sobre el modelo intercultural en los estudiantes de la Universidad Intercultural de Chiapas, mediante la aplicación de entrevistas con las que recolectó el discurso; al mismo tiempo se efectúa un análisis comparativo entre los discursos institucionales y los apropiados por los estudiantes. El trabajo es de corte cualitativo. Dentro de los principales resultados se percibe a la interculturalidad como algo aún no logrado "Otro tema 
importante son sus percepciones sobre el ejercicio de la interculturalidad en la universidad. Curiosamente, aquí no hay una diversidad de opiniones, sino una ligera tonalidad de decepción porque, según ellas y ellos, la interculturalidad difícilmente se logra en la UNICH" (Tipa, 2017, p. 28). El autor concluye que aún no existen ideas cimentadas con base en la interculturalidad entre la institución y los estudiantes. Se manifiestan discursos en donde los estudiantes comentan los actos de discriminación en la institución siendo este la principal razón por la que se no se logra la interculturalidad.

La interculturalidad, como medida para disminuir la discriminación, es un tema en discusión dentro de los foros académicos como el organizado por la Universidad Iberoamericana en marzo del 2020, donde la mesa titulada "Educación y diversidades: Equidad, interculturalidad e inclusión”, y representada por un grupo de académicos expertos concluyó que:

Es necesario plantearnos nuevas maneras de pensar lo intercultural en la escuela, que trascienda la visión de una inclusión supuestamente armónica de grupos culturalmente diversos y trabaje por una convivencia real, respetuosa y en igualdad de derechos entre personas y grupos sociales: desde las desigualdades, desde el racismo y la discriminación, para abrirnos a concebir nuevas epistemologías y modos distintos de entender y de hacer en el mundo (Sartorello y Dietz, 2020, p. 1)

Lo anterior responde al hecho de que la educación intercultural en México es implementada solo para los pueblos indígenas, reduciendo así la incorporación de este tópico en la educación superior, al respecto, Sartorello y Dietz (2020) comentan que, "todavía hay grandes retos por enfrentar: la educación intercultural en la gran mayoría de los casos no atiende a todo el estudiantado del país, sino que se sigue focalizando preferencialmente a la niñez indígena en contextos rurales de origen" (p. 1).
Sandoval, Guerra y Meraz (2010), realizaron un estudio en el que entrevistaron a 10 funcionarios de instituciones interculturales en México, tales como la Coordinación General de Educación Intercultural y Bilingüe (CGEIB) y universidades interculturales como la del Estado de México, la de Veracruz y la de Chiapas. En el texto se exponen las visiones sobre la interculturalidad de las autoridades institucionales, ya que los autores defienden que, "al ostentar el cargo principal en estas instituciones la figura del rector, su percepción de lo que considere asertivo con respecto a lo que es o deja de ser la interculturalidad, influye sobremanera en el desarrollo de los programas, planes y en las formas en que se realice o no esa relación entre culturas. (Sandoval, et al., 2010, p. 38).

\section{Metodología}

Las preguntas generales que funcionan de guía para esta investigación son las siguientes: ¿cuáles son las representaciones sociales de los académicos de la Universidad Veracruzana sobre la interculturalidad? y ¿qué tanto convergen los académicos de la Universidad Veracruzana con el proyecto institucional acerca de la interculturalidad?

En esta investigación fue necesario precisar los métodos y las técnicas empleadas para su desarrollo, se seleccionó la metodología mixta (Dorantes, 2018), por la riqueza que implica, también se obtuvo una valoración completa en cuanto a la interculturalidad, poniendo énfasis en lo que los datos demuestran (cuantitativamente) y lo que los sujetos opinan (cualitativamente), Rojas (1995).

La población de estudio se integra por 121 académicos de las diferentes Áreas Académicas de la Universidad Veracruzana en la región Xalapa. Las encuestas se distribuyeron de la siguiente manera:

- Área Económica - Administrativa: 21 académicos

- Área de Humanidades: 29 académicos

- Área de Ciencias de la salud: 21 académicos

- Área de Artes: 19 académicos

- Área Técnica: 15 académicos

- Área Biológica agropecuaria: 16 académicos 
Se empleó la encuesta como medio principal para la obtención de los datos, con la pregunta detonante "mencione 5 palabras con las que usted asocie el proyecto intercultural de la UV" relacionada al método de asociación libre de Abric (1994) el cual consiste en:

a partir de un término inductor (o de una serie de términos), en pedir al sujeto que produzca todos los términos, expresiones o adjetivos que se le presenten espíritu. El carácter espontáneo por lo tanto menos controlado y la dimensión proyectiva de esa producción deberían permitir así tener acceso, mucho más rápido y fácil que en una entrevista, a los elementos que constituyen el universo semántico del término o del objeto estudiado (1994, p. 59).

Las categorías que se utilizaron fueron las de actitud, información y campo de representación, estas traen consigo las variables, educación intercultural, competencias interculturales y políticas institucionales, en el pilotaje participaron académicos de la Facultad de Pedagogía y la Facultad de Ciencias Administrativas y Sociales de la UV.

Utilizar este método contribuyó a capturar las representaciones sociales y dar cuenta de las subjetividades sobre la interculturalidad de los académicos de la UV, dichas palabras fueron procesadas por el software IraMUteQ (Molina, 2017), creando nubes de palabras y un árbol de similitud.

La otra parte de la recolección de datos se realizó en función de conocer el discurso intercultural institucional, para ello se aplicó la técnica denominada análisis de contenido o análisis textual o documental, la cual es definida por (Cadena, P., Rendón, R., Aguilar, J., Salina, E., Cruz, R. y Sangerman, M. 2017): "para estudiar y analizar la comunicación de manera objetiva, sistemática y cuantitativa, que permite hacer inferencias válidas y confiables de datos con respecto a su contexto" (p. 1,615). Para ello, durante aproximadamente seis meses se procedió a recabar el discurso plasmado en los documentos oficiales de la universidad, como se ha mencionado en los apartados anteriores, se hizo un rastreo sobre tópicos relacionados a la interculturalidad, el discurso recolectado fue procesado por el software IraMuTeQ (Molina, 2017), dando lugar a la nube de palabras institucional construida con el discurso rescatado del Estatuto General, la Ley Orgánica, el Código de Ética y la Ley de Autonomía de esta institución.

Para formar las nubes de palabras se utilizó la técnica de asociación libre, propuesta por Abric (1994). Se debe entender por asociación de palabras como:

Es "una producción verbal (...), permite reducir la dificultad o los límites de la expresión discursiva a partir de un término inductor (o de una serie de términos), y en pedir al sujeto que produzca todos los términos, expresiones o adjetivos que se le presenten al espíritu. Es de carácter espontáneo por lo tanto menos controlado y la dimensión proyectiva de esa producción permite tener acceso, mucho más rápido y fácil que en una entrevista a los elementos que constituyen el universo semántico del término o del objeto estudiado. La asociación libre permite el acceso a los núcleos figurativos de la representación. (Abric, 1994, p. 59)

Los procedimientos de análisis de una producción de asociaciones libres permiten extraer los elementos organizadores del tópico elegido, por ende, se recolectaron las palabras clave sobre interculturalidad, a partir del término inductor: "proyecto intercultural de la UV"; por lo que se les pidió a los encuestados, académicos de la UV, escribir cinco (5) palabras que le vinieran a la mente cuando se habla del término inductor.

\section{Resultados}

En este apartado se evidencian los análisis de los datos obtenidos mediante la encuesta aplicada a los académicos de la Universidad Veracruzana, por ende, se exponen las representaciones sociales construidas y la descripción debida. 
Asimismo, se presentan las nubes de palabras construidas producto de la asociación que los profesores de la UV realizaron sobre "proyecto intercultural UV". También, las nubes que son producto de la investigación realizada con los documentos institucionales de la Universidad Veracruzana.

Enseguida, se muestran los datos generales que se desprenden de la encuesta aplicada a 121 acadé- micos. Es importante aclarar, que en los gráficos de barras los datos que se exhiben en cada una de ellas representa una opción de respuesta que equivale al $100 \%$, y esto permite describirlas una a una en cada gráfico.

\section{Indique en qué casos le parece importante incluir en su clase estudiantes}

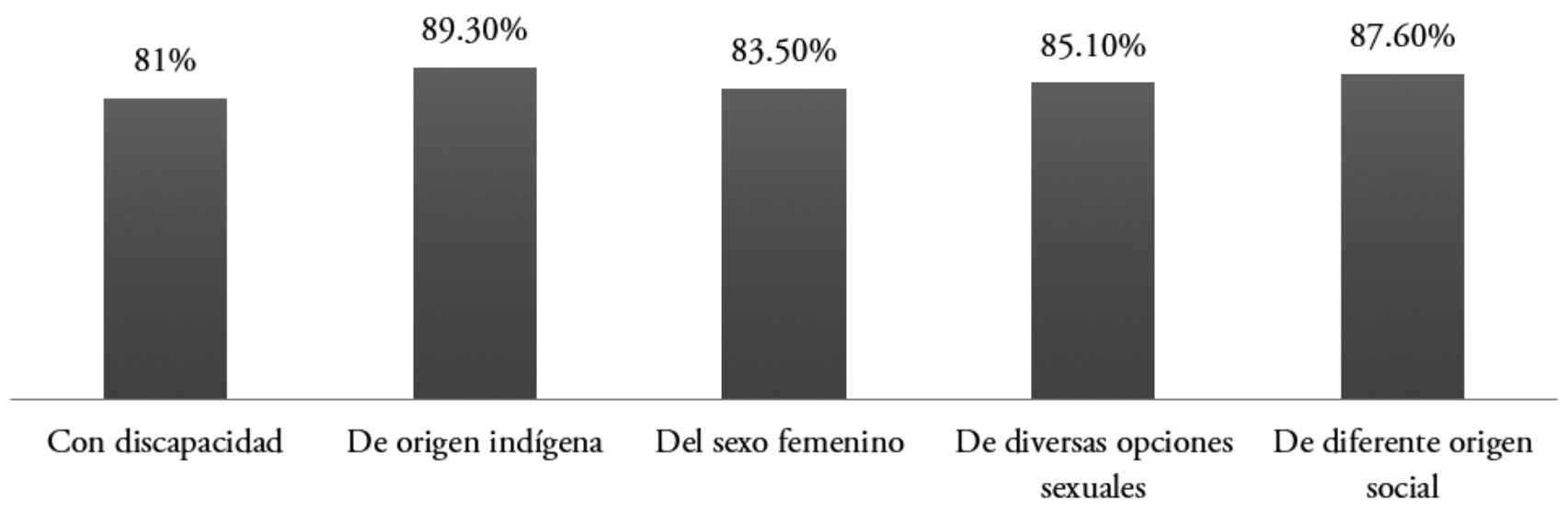

Figura 1. Inclusión de estudiantes en las aulas

Fuente: elaboración propia.

Observamos que el $81 \%$ de los académicos encuestados, están de acuerdo con incluir estudiantes "con discapacidad" en sus aulas, el $19 \%$ no comparte la idea. El 89 \%, manifestó estar de acuerdo con incluir estudiantes "de origen indígena" en su clase, y el $11 \%$ manifestó que no lo haría. El 83 \% de los académicos consideró importante incluir en su clase a estudiantes "del sexo femenino", mientras que el $17 \%$ dijo que no está de acuerdo. El $85 \%$ de los académicos, señaló que es importante incluir en su clase estudiantes "de diversas opciones sexuales", mientras que el $15 \%$ no está de acuerdo en incluirlos; finalmente, al $87 \%$ de los académicos les parece importante incluir en su clase a estudiantes de diferente origen social, mientras que el $13 \%$ no los incluiría. De manera general, entre 9 y 8 de cada diez, incluyen a los estudiantes en clase por sus diferencias de: discapacidad, origen indígena, sexo, diversidad sexual y origen social. No obstante, debemos cuestionarnos sobre ese porcentaje de profesores que no consideran importante incluir estudiantes de esa índole, primero, porque en términos absolutos es muy preocupante la experiencia escolar de sus alumnos, pero también porque se reproduce el racismo y la exclusión. 


\section{Como profesor de la UV}

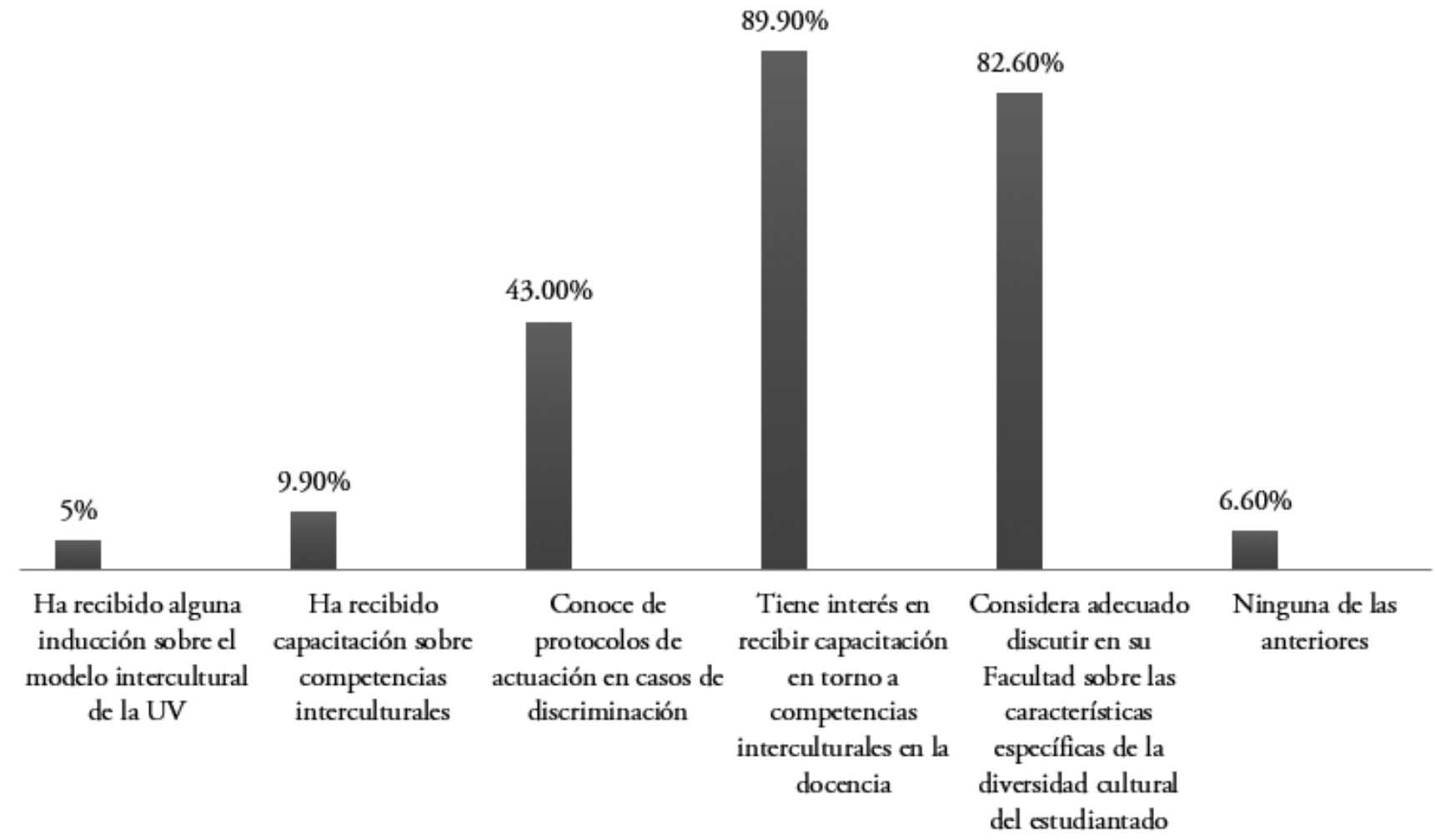

Figura 2. Conocimiento e inducción al modelo intercultural de la Universidad Veracruzana.

Fuente: elaboración propia.

$\mathrm{Al}$ analizar la pregunta referente "como profesor de la UV”, los académicos encuestados respondieron lo siguiente: $5 \%$ considera que sí ha recibido alguna inducción sobre el modelo intercultural de la UV, mientras que el $95 \%$ no ha recibido ninguna inducción. El 9.90 \% manifestó que sí ha recibido capacitación sobre competencias interculturales, pero de manera contradictoria y en su gran mayoría con el $90.10 \%$, señaló que no ha recibido capacitación. El $43 \%$ de los académicos respondieron que sí conocen los protocolos de actuación en caso de discriminación, mientras que el $57 \%$ los desconoce. El $89 \%$ sí tiene interés en recibir capacitación en torno a las competencias interculturales en la docencia, mientras que el $11 \%$ no lo tiene. El $82 \%$ sí considera adecuado discutir en su Facultad sobre las caracterís- ticas específicas de la diversidad cultural del estudiantado mientras que el $18 \%$ no lo considera adecuado. El $6 \%$ no considera importante o necesario ninguna de las anteriores.

\section{Las imágenes de los profesores}

En este apartado, se da el inicio al análisis de una pregunta abierta que se incluyó en el cuestionario, su análisis es cualitativo; se muestran las nubes producto de organizar mediante un corpus las palabras obtenidas de los profesores al leer "proyecto intercultural”. Las palabras requeridas por la encuesta eran cinco (5), por lo que la siguiente nube está compuesta por 605 palabras. 


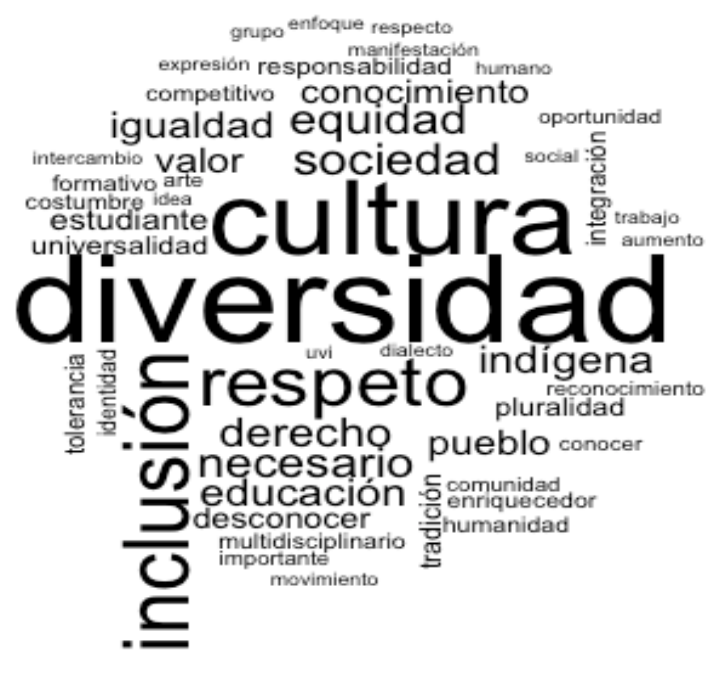

Figura 3. Representaciones sobre interculturalidad. Nube de palabras de los académicos cuando piensan en el proyecto intercultural de la UV

Fuente: elaboración propia.

La nube anterior demuestra la asociación de conceptos e ideas que los académicos comparten de forma general en la región Xalapa. Como se observa en la nube, la idea central que se tiene sobre el proyecto intercultural es "diversidad", seguido por la de "inclusión" y "cultura", siendo estas los componentes del primer nivel de análisis.

En el segundo se observan las palabras o ideas que se encuentran a la periferia del primer análisis, en ella se encuentran: "respeto", "sociedad", "indígena”, "equidad" y "derecho". En el tercer perímetro, se encuentran ideas como "tolerancia”, "integración", "multidisciplinar", "conocimiento", "competitivo" y "necesario".

La representación social de los académicos está compuesta como una visión fragmentada de la interculturalidad, es decir, contiene entre su discurso elementos que integran el paradigma en general, como se ve en los dos primeros perímetros.
No obstante, es importante mencionar que dentro de la nube está la palabra "dialecto", aunque es en pequeña proporción, ya que se ubica en el perímetro más pequeño, denota que aún hay conceptos y percepciones erróneas de los idiomas indígenas. Dentro de la nube se aprecia la palabra "desconocido", que no es más que la poca información o nula que tienen sobre el proyecto intercultural de la UV.

Es de relevancia decir que, dentro de la nube no se encuentran ideas en cuanto a la protección de los derechos humanos a través de bases jurídicas. La nube está compuesta principalmente con una percepción valorativa de la interculturalidad, en cuanto a cuestiones morales; se aprecia poco sobre educación.

Si tratamos de hilar en forma discursiva las representaciones sociales que tienen los académicos de la UV acerca del proyecto intercultural institucional, podemos concluir que los académicos de la Universidad Veracruzana conciben al proyecto intercultural a través de términos como cultura, diversidad e inclusión; como ejes centrales, consideran el fomento del respeto hacia los indígenas en las instituciones educativas, siendo una necesidad dentro de la educación promover valores como la equidad, la igualdad, la tolerancia y la identidad mediante acciones de integración y reconocimiento de la pluralidad dentro de los campos multidisciplinares y de conocimiento. Sin embargo, desconocen la importancia de conocer, aceptar y promover la diversidad, y el valor de los estudiantes con manifestaciones culturales diferentes. Desafortunadamente, cuentan dentro de su discurso con palabras como dialecto, que en México suele tener una acepción peyorativa ya que se considera como inferior a la lengua oficial (Manrique 1994; Zolla y Zolla 2004; Moreno, 2006; Comisión Nacional de los Derechos Humanos, 2016). Al mismo tiempo, los profesores consideran un aumento de trabajo atender la pluralidad en las aulas. 


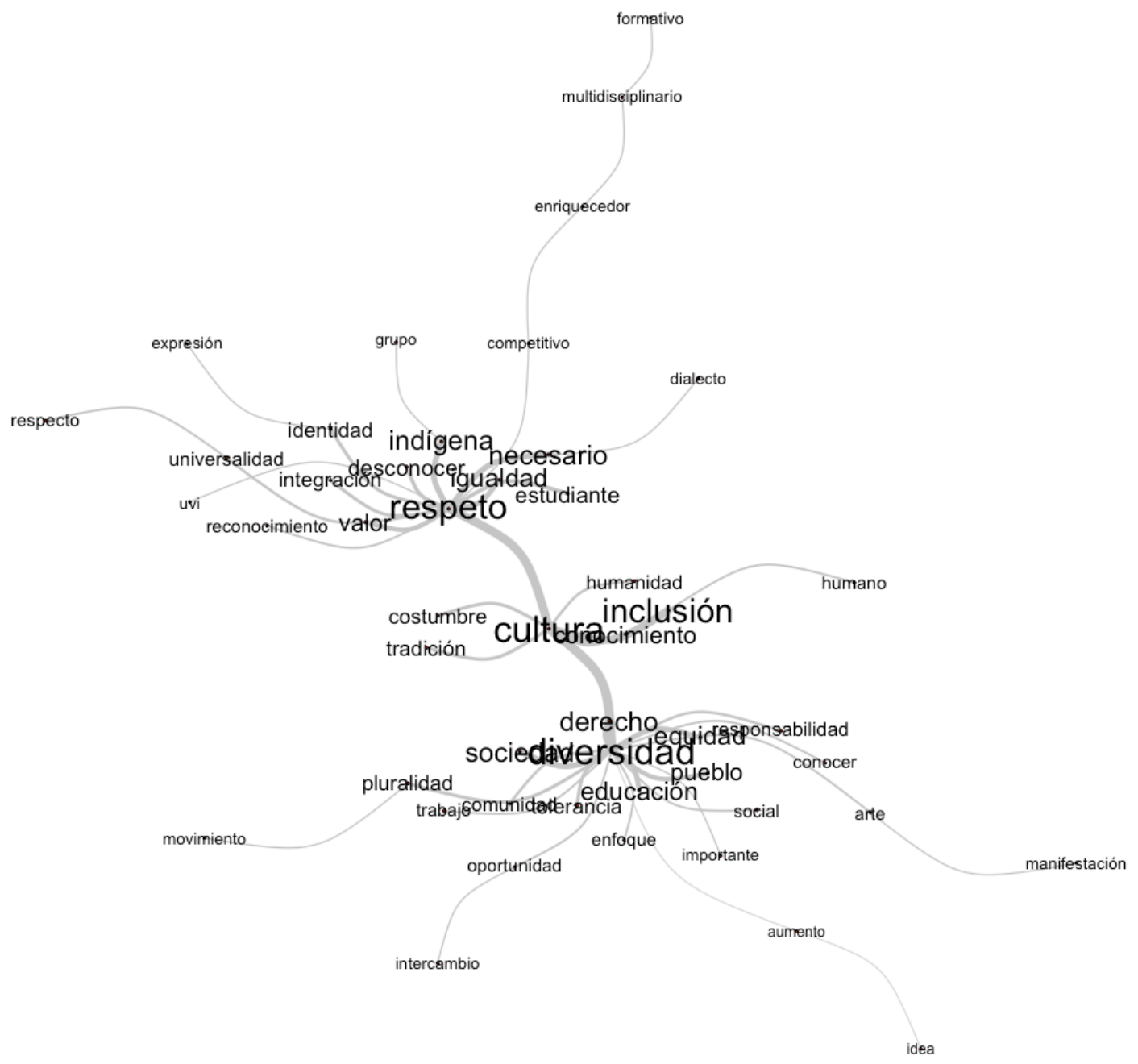

Figura 4. Representaciones sobre la interculturalidad. Análisis de similitud de los académicos cuando piensan en el proyecto intercultural de la UV

Fuente: elaboración propia.

Como se aprecia, existen tres grandes campos semánticos en cuanto a la captura del discurso de los académicos mediante las palabras. El primero, alrededor de la palabra cultura, donde se puede distinguir que hacen conexión con costumbre, tradición, inclusión y humanidad. El segundo campo con la palabra respeto, despliega una serie de ideas en cuanto a valores, ya que se enuncian palabras como: integridad, reconocer, valor y necesario. También se aprecian palabras como indígena y estudiante, lo cual permite conocer que se distingue a los estudiantes indígenas. Finalmente, el tercer campo con la palabra diversidad engloba entre su contexto ideas como educación, responsabilidad, equidad, pluralidad sociedad y pueblo.

En la siguiente tabla se encuentran las representaciones sociales de los académicos de la UV, sobre la imagen de interculturalidad en donde se aprecian las similitudes y diferencias por Área Académica. 


\begin{tabular}{|c|c|c|c|}
\hline $\begin{array}{l}\text { Dimensiones de las } \\
\text { RS Área Académica }\end{array}$ & $\begin{array}{l}\text { Campo de } \\
\text { representación }\end{array}$ & Información & Actitud \\
\hline $\begin{array}{l}\text { Económico } \\
\text { administrativa }\end{array}$ & $\begin{array}{l}\text { Persona, } \\
\text { universitario }\end{array}$ & $\begin{array}{l}\text { Derecho, seguridad, acción, } \\
\text { sociedad, humano, trato, } \\
\text { discriminación, jurídico }\end{array}$ & $\begin{array}{l}\text { Igualdad, respeto, libertad, } \\
\text { dignidad, igual, respetar, libre, } \\
\text { promover, seguridad, evitar }\end{array}$ \\
\hline Artes & Diversidad & $\begin{array}{l}\text { Inclusión, cultural, expresión, } \\
\text { arte, estudiante. }\end{array}$ & $\begin{array}{l}\text { Valor, igualdad, } \\
\text { respeto }\end{array}$ \\
\hline Humanidades & Diversidad & $\begin{array}{l}\text { Cultural, educación, } \\
\text { inclusión }\end{array}$ & $\begin{array}{l}\text { Respeto, igualdad, humano, } \\
\text { humanidad, responsabilidad }\end{array}$ \\
\hline Técnica & Cultura & $\begin{array}{l}\text { Diversidad, educación, } \\
\text { tradición }\end{array}$ & Igualdad, respeto, necesario \\
\hline $\begin{array}{l}\text { Biológica } \\
\text { agropecuaria }\end{array}$ & Multidiscplinario & $\begin{array}{l}\text { Necesidad, diversidad, } \\
\text { universalidad, onocimiento, } \\
\text { competitivo }\end{array}$ & $\begin{array}{l}\text { Equidad, respeto, inclusión, } \\
\text { tolerancia }\end{array}$ \\
\hline Ciencias de la salud & $\begin{array}{l}\text { Cultura y } \\
\text { diversidad }\end{array}$ & $\begin{array}{l}\text { Inclusión, pluralidad, } \\
\text { indígena }\end{array}$ & Necesario, derecho, equidad \\
\hline
\end{tabular}

Figura 5. Representaciones sociales por Área Académica

Fuente: elaboración propia.

Como puede observarse, aunque hay una visión general compartida sobre la interculturalidad, las tradiciones científicas y disciplinarias (Clark, 1987; Becher, 2001; y Trowler, 2001), los ethos específicos (Merton, 1996) y las prácticas sociales de los investigadores (Grediaga, 2000) de cada disciplina representan configuraciones intelectuales específicas. Unos comparten una visión más juridicista, otros hacen referencia a la educación y a los estudiantes.

\section{La imagen institucional}

En este apartado revisaremos la perspectiva institucional a través de la revisión de sus principales documentos. Más allá de los discursos de las autoridades, el sentido intercultural ha penetrado poco en los documentos oficiales y todavía no atraviesa plenamente la legislación.

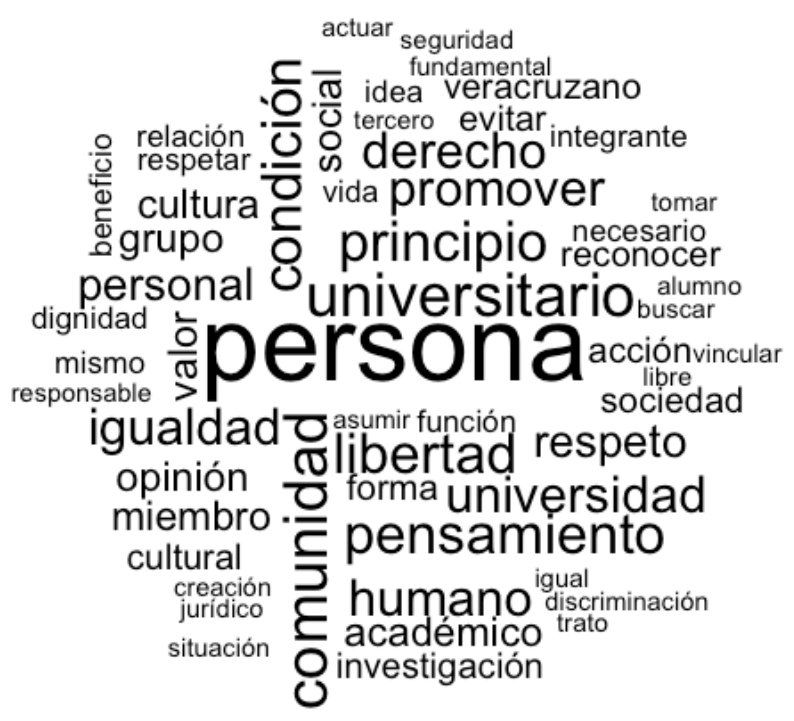

Figura 6. Nube de palabras institucional

Fuente: elaboración propia. 
Derivado de la nube de palabras observamos los siguientes elementos que conforman la representación social que deriva de los documentos oficiales de la Institución: en la dimensión campo, la palabra dominante es "persona", la cual se vincula a las siguientes palabras: "universitario, comunidad, condición social, libertad, universidad, pensamiento, igualdad, respeto, humano, académico, etc.”.

En términos de la actitud, logramos observar que existe una postura positiva cuando se habla de interculturalidad, pues las manifestaciones de: dignidad, igual, respeto, respetar, libre, promover, seguridad, evitar, hablan de una interiorización del docente por el reconocimiento a la interculturalidad. Cuando consultamos los documentos oficiales de la UV se halla que estos aspectos sí se enuncian, con una clara postura a favor de la interculturalidad, la cual se fortalece en cuanto a información y conocimiento, en la nube de palabras se observa que se enuncian las palabras derecho, seguridad, acción, sociedad, humano, trato, discriminación, jurídico, igualdad, dignidad, persona, cultura, grupo, respeto y condición social.

En términos sintéticos, a partir de la descripción de la nube de palabras institucional, se puede afirmar que la interculturalidad en los documentos oficiales de la UV (Ley Orgánica, Ley de Autonomía, Estatuto General y Código de Ética) pone énfasis en la persona como ente universitario, el cual asume su rol en la comunidad estudiantil, la Universidad promueve la libertad, la igualdad, el libre pensamiento y el respeto entre académicos y estudiantes. También indica que es necesario reconocer los derechos jurídicos, evitando tratos de discriminación, a su vez busca vincular a cada miembro de la sociedad a asumir la responsabilidad de una sociedad diversa y lo que esta conlleva, promoviendo la dignidad humana de los grupos con cultura, opiniones, acciones o en situaciones diferentes a las dominantes.

\section{Conclusiones}

Las representaciones sociales de los académicos de la Universidad Veracruzana sobre la interculturalidad son variadas. Los académicos tienen una representación cimentada en entender la intercultu- ralidad a través de la "diversidad", se conoce sobre ella y comparten actitudes proclives al tema, como el respeto, la igualdad, la equidad, la tolerancia.

En ese sentido, el análisis cuantitativo expresado en las gráficas denota una controversia, en cuanto a lo que saben, lo que hacen y lo que reciben, es decir, saben sobre inclusión y diversidad cultural, sin embargo, carecen de información proporcionada por la Universidad. Mientras que los datos revelan un interés fuerte en los académicos por aprender más sobre estos contenidos. También existen excepciones, ya que hay académicos que aún demuestran poco conocimiento sobre la interculturalidad, y en los casos más extremos, total desinterés, lo cual es preocupante.

En contraparte, la representación institucional sobrevalora a la "persona", por lo que se infiere que los considera fundamentales en este proceso; no obstante, entre la información mostrada se encuentran contenidos sobre educación, derechos, comunidad e investigación, y, al mismo tiempo, una actitud a favor, ya que hay elementos como la igualdad, la equidad y el respeto.

Se debe mencionar que la interculturalidad no es propia de un Área Académica o de una ciencia, sino que es capaz de transversalizar en los diferentes campos de conocimiento, y aquí en este artículo son más que obvios, ya que al analizar las diferentes Áreas, todos los académicos al menos habían escuchado el término leído y mostraron sus representaciones sociales con base en ello.

Las visiones en cuanto a la interculturalidad no convergen en un proyecto en común, por lo que denota una problemática entre las concepciones de los académicos y las institucionales, ya que así se brinda una filosofía fragmentada para trabajar con base en conocimientos interculturales dentro de las aulas de la Universidad Veracruzana.

Esto es un problema común en otras universidades, tal como se ha observado en otras investigaciones (Hernández, 2017; Tipa, 2017 o Sandoval et. al, 2010), y es probable que esté asociado con diferentre concepciones, o el sentido polisémico del término. Sin embargo, podríamos coincidir en que la 
interculturalidad es un concepto que con el tiempo se va transformando, y confiar en que progresivamente cada institución irá madurando sus propias definiciones para alcanzar una mayor cohesión institucional. En efecto, si las representaciones se aproximan y llegaran a coincidir, entonces las prácticas serían más coherentes y las estrategias para luchar contra la discriminación y la exclusión a nivel universitario serían más efectivas.

\section{Referencias}

Abric, J. (1994). Prácticas sociales y representaciones. México: Ediciones Coyoacán.

Abric, J. (2005). Méthodes d'étude des représentations sociales. Toulouse: ERES. Doi:10.3917/eres. abric.2003.01.

Abric, J. (2008). Psychologie de la communication: théories et méthodes. Paris: Armand Colin.

Aguado, M. (2011). El enfoque intercultural en la búsqueda de buenas prácticas escolares. Revista Latinoamericana de Inclusión Educativa. Recuperado de: https://www.oei.es/historico/es 141. htm

Becher, T. (2001). Tribus y territorios académicos: la indagación intelectual y las culturas de las disciplinas. Barcelona: Gedisa.

Cadena, P., Rendón, R., Aguilar, J., Salina, E., Cruz, R. y Sangerman, M. (2017). Métodos cuantitativos, métodos cualitativos o su combinación en la investigación: un acercamiento en las ciencias sociales. Revista Mexicana de Ciencias Agrícolas, 8: 7.

Casillas, L. y Villar, S. (2009). Universidad Intercultural Modelo Educativo. México: SEP.

Casillas, M., Badillo, J. y Ortiz, V. (2012). Educación Superior para indigenas y afrodescendientes en América Latina. México: Universidad Veracruzana, Dirección General del Área Académica de Humanidades.

Clark, B. (1987). The Academic Profession. National, Disciplinary, and Institucional Settings. Estados Unidos de América: Universidad de California.
Comisión Nacional de los Derechos Humanos. (2016). Derechos lingüisticos de los pueblos indígenas. México: Comisión Nacional de los Derechos Humanos. Recuperado de: http://www.cndh.org. $\mathrm{mx} /$ sites/all/doc/cartillas/2015-2016/19-dh-linguisticos.pdf

Constitución Política de los Estados Unidos Mexicanos. (2019). Artículo 3․ Recuperado de http://www.ordenjuridico.gob.mx/Constitucion/cn16.pdf

Encuesta Nacional sobre Discriminación (ENADIS). (2017). Principales Resultados. Recuperado de https://www.conapred.org.mx/userfiles/files/ PtcionENADIS2017_08.pdf

Diario Oficial de la Federación. (2019). Ley general de educación de 1993. Recuperado de https://dof.gob.mx/nota_detalle.php?codigo $=5573858 \&$ fecha $=30 / 09 / 2019$

Diario Oficial de la Federación. (2018). Ley General de Derechos Lingüísticos de los Pueblos Indígenas de 2003. Recuperado de http://www.diputados.gob.mx/LeyesBiblio/ pdf/257_200618.pdf

Diario Oficial de la Federación. (2018). Ley Federal para Prevenir y Eliminar la Discriminación de 2003. Recuperado de: http://www.diputados. gob.mx/LeyesBiblio/pdf/262_210618.pdf

Dorantes, J. (2018). La aventura de investigar, es una tarea que se aprende en la Universidad. Revista Interconectando Saberes. Revista de Divulgación del Instituto de Investigaciones y Estudios Superiores Económicos y Sociales de la Universidad Veracruzana, 6(3), 171-185.

Grediaga, R. (2000). Profesión académica, disciplinas y organizaciones: procesos de socialización académica y sus efectos en las actividades y resultados de los académicos mexicanos. México: Anuies.

Hernández, I. (2017). Las y los estudiantes de la Universidad intercultural de Chiapas: representaciones sociales $y$ relaciones interculturales en la vida cotidiana escolar. [Tesis de Maestría] Centro de investigaciones y estudios superiores en antropología social, CIESAS Pacífico Sur, Oaxaca de Juárez, Oaxaca. 
Jodelet, D. (2008). El movimiento de retorno al sujeto y el enfoque de las representaciones sociales. Cultura y Representaciones Sociales 3(5), 32-63.

Jodelet, D. (2000). Representaciones sociales: contribución a un saber sociocultural sin fronteras. En D. Jodelet, A. Guerrero (eds.). Develando la cultura. (1era. ed.). México: Universidad Nacional de México.

Jodelet, D. (1986). La representación social: fenómenos, concepto y teoría. En S. Moscovici, (ed.). Psicología Social II. Barcelona: Paidós.

Malaga, S. (2016). El significante interculturalidad. Categorías analíticas frente a un breve estado de conocimiento. En Z. Navarrete y J. Loyola (eds.), Formación de sujetos, reformas, políticas y movimientos sociales. (pp. 50-66). México: Programa de análisis político de discurso e investigación: Plaza y Valdés, S.A DE C.V.

Manrique, L. (1994). La población indigena mexicana. México: INEGI-INAH-ISS/UNAM.

Mato, D. (2009). Las iniciativas de los movimientos indígenas en educación superior: un aporte para la profundización de la democracia. Revista Nueva Sociedad, 227. ISSN: 0251- 3552.

Merton, R. (1996). The Ethos of Science. In P. Sztompka (ed.). On Social Structure and Science. (pp. 267-276). Chicago: University of Chicago Press.

Molina, J. (2017). Tutorial para el análisis de textos con el software IRaMuTeQ. Barcelona: Grupo de Investigación DHIGES-University of Barcelona. Recuperado de https://www.researchgate. net/publication/3156965508.

Moreno, J. (2006). La dignidad e igualdad de las lenguas. Crítica a la discriminación lingüistica. Madrid: Alianza.

Moscovici, S. (1979). El psicoanálisis, su imagen y su público. Buenos Aires: Huemul

Naciones Unidas. (1948). Declaración Universal de los Derechos Humanos (DUDH). Recuperado de https://www.ohchr.org/EN/UDHR/Documents/UDHR_Translations/spn.pdf
Organización de las Naciones Unidas para la Educación, la Ciencia y la Cultura (UNESCO). (2015). Construyendo Igualdad en la Educación Superior. Fundamentación y lineamientos para transversalizar los ejes de igualdad y ambiente. Quito: SENESCYT/UNESCO

Rojas, R. (1995). Investigación-acción en el aula. Enseñanza aprendizaje de la metodología. México: Plaza y Valdés.

Sandoval, A. y Guerra, E. (2007). La interculturalidad en la educación superior en México. $R a$ XIMAHI, 2(3), 273-288.

Sandoval. E, Guerra, E. y Meraz, M. (2010). Las dimensiones de la interculturalidad: el discurso de los rectores de las Universidades Interculturales. En E. Sandoval, et al., (coord.). Politicas públicas de educación superior intercultural y experiencias de diseños educativos. Recuperado de http://www.eumed.net/libros/2010e/830/ indice.htm

Sartorello, S. y Dietz, G. (2020). Foros Ibero / Educación y diversidades: Equidad, interculturalidad e inclusión. Educación Futura. Recuperado de: https://www.educacionfutura.org/foros-ibero-educacion-y-diversidades-equidad-interculturalidad-e-inclusion/

Schmelkes, S. (2013). Educación para un México intercultural. Sinéctica, Revista Electrónica de Educación, (40), 1-12. ISSN: 1665-109X. Recuperado de https://www.redalyc.org/articulo.oa?id=998/99827467007

Téllez, S., Sandoval, J. y González, O. (2006). Intercultural University of Veracruz: a holistic project promoting intercultural education. Intercultural Education, 17(5), 499-506. Recuperado de https://www.tandfonline.com/doi/ abs/10.1080/14675980601063843

Tipa, J. (2017). ¿La interculturalidad es más que una palabra? La interculturalidad según estudiantes de la Universidad Intercultural de Chiapas. Antrópica. Revista De Ciencias Sociales Y Humanidades, 3(6), 17-34. Recuperado a partir de https://www.antropica.com.mx/ojs/index.php/ AntropicaRCSH/article/view/120 
Trowler, P. (2001). Academic tribes and territories. Reino Unido: McGraw-Hill Education.

UNESCO. (2015). Objetivos de desarrollo sostenible. Recuperado de: https://www.un.org/ sustainabledevelopment/es/objetivos-de-desarrollo-sostenible/

UNESCO. (2017). Competencias interculturales, marco conceptual y operativo. Recuperado de: https:// issuu.com/catedraunescounal/docs/competencias_interculturales

Universidad Veracruzana (UV). (1996). Ley Orgánica. Recuperado de https:/www.uv.mx/legislacion/ files/2019/04/Ley-Organica-Universidad-Veracruzana- reimpresion2017.pdf

Universidad Veracruzana (UV). (2000). Ley de Autonomía. Recuperado de https://www.uv.mx/ legislacion/files/2017/07/Ley-de-Autonomia-Universidad-V eracruzana.pdf
Universidad Veracruzana (UV). (2012). Estatuto General. Recuperado de https://www. uv.mx/legislacion/files/2018/12/Estatuto-General-3-12-2018.pdf

Universidad Veracruzana (UV). (2016). Código de Ética. Recuperado de https:/www.uv.mx/ legislacion/files/2017/07/Codigo-de-etica-de-la-Universidad-V eracruzana.pdf

Velasco, S. \& Jablonska, Z. (2010). Construcción de politicas educativas interculturales en México: debates, tendencias, problemas, desafíos. México: Universidad Pedagógica Nacional.

Zolla, C. \& Zolla, E. (2004). Los pueblos indigenas de México, 100 preguntas. México: UNAM. 